\title{
BMJ Open Cross-sectional study on the awareness, susceptibility and use of heated tobacco products among adolescents in Guatemala City, Guatemala
}

\author{
Anna Gottschlich (D) , ${ }^{1,2}$ Sophia Mus, ${ }^{1}$ Jose Carlos Monzon, ${ }^{1}$ James F Thrasher, ${ }^{3,4}$ \\ Joaquin Barnoya (D) ${ }^{1,5}$
}

To cite: Gottschlich A,

Mus S, Monzon JC, et al. Cross-sectional study on the awareness, susceptibility and use of heated tobacco products among adolescents in Guatemala City, Guatemala. BMJ Open 2020;10:e039792. doi:10.1136/ bmjopen-2020-039792

- Prepublication history for this paper is available online. To view these files, please visit the journal online (http://dx.doi org/10.1136/bmjopen-2020039792).

Received 27 April 2020 Revised 20 0ctober 2020 Accepted 17 November 2020

Check for updates

(C) Author(s) (or their employer(s)) 2020. Re-use permitted under CC BY-NC. No commercial re-use. See rights and permissions. Published by BMJ.

For numbered affiliations see end of article.

Correspondence to Dr Anna Gottschlich; annagott@umich.edu

\section{ABSTRACT}

Objectives Heated tobacco products (HTPs) are increasingly marketed worldwide, yet limited research on HTPs has been conducted in low and middle-income countries (LMICs) or among adolescents. Guatemala is one of the few LMICs where HTPs are available. This study examined prevalence and correlates of HTP awareness, susceptibility and use among adolescents in Guatemala. Design, setting and participants A cross-sectional survey on HTP awareness, susceptibility and use was conducted among 2870 students between the ages of 13 and 17 in private schools in Guatemala City, Guatemala. Primary and secondary outcome measures The primary outcome was susceptibility to future use of HTP among school-aged current and never smokers in Guatemala. We also explored awareness and use of HTPs. Multivariate binomial regression models were used to explore associations between these outcomes and both sociodemographic factors and established smoking correlates.

Results Of all students ( $n=2870)$, about half were aware of HTPs (52.4\%) and susceptible to future or continued use $(52.4 \%)$. Whereas $8.4 \%$ of students had tried HTPS in the lifetime (but not in the last month), only $2.9 \%$ used HTPs in the past month. Independent correlates of HTP susceptibility and ever-use included: use of other tobacco products (current smoking: adjusted $O R(A O R)=10.53$ and 6.63 , respectively; current e-cigarette use: $\mathrm{AOR}=21.87$ and 10.40 , respectively), moderate alcohol consumption ( $A 0 R=1.49$ and 1.19, respectively), marijuana use in the past 30 days ( $A 0 R=3.49$ and 2.29 , respectively) and having friends who use HTPs (AOR=1.83 and 7.28, respectively).

Conclusions Among this sample of adolescents in Guatemala City, where tobacco control is weak, the prevalence of HTP use was low but susceptibility to future use was high. Tobacco prevention and intervention strategies for cigarettes and e-cigarettes should now also include HTPs, which tend to be used by similar adolescent populations (ie, those who use other substances or are exposed to tobacco through family and friends).

\section{INTRODUCTION}

The increase in popularity of nonconventional tobacco products has further
Strengths and limitations of this study

- Heated tobacco products (HTPS) are increasingly popular in countries where available, but little is known about adolescent use in low and middleincome countries with weak tobacco control policies like Guatemala.

- The study sample was selected from private high school students in Guatemala City, specifically to oversample potential HTP users but also resulted in a population not generalisable nationwide.

- This study used a previously fielded questionnaire adapted to Guatemala, and research questions, outcomes and analysis were based on prior local work.

- Both the population of interest and public were involved in study design and implementation: a subset of students were asked to pilot and comment on the survey before implementation, participating schools were asked to review the protocol and the Ministry of Health gave support of this study with the understanding that results will be shared and used to support tobacco control strategies.

- The data are self-reported, thus there is a chance of misreporting, particularly under-reporting due to social desirability bias.

complicated an already challenging tobacco control landscape. For example, electronic cigarettes (e-cigarettes) increasingly appear more appealing to adolescents than conventional cigarettes; a considerable proportion of adolescent e-cigarette users have never smoked conventional cigarettes. ${ }^{1}{ }^{2}$ The appeal of e-cigarettes in younger populations is a key argument for strong regulations that would decrease youth access (eg, increase price and legal age of purchase) and appeal (eg, banning flavours and marketing), often outweighing arguments that policies should promote e-cigarette use among established smokers who may benefit from consumption of a less harmful product. ${ }^{3}$ Recently, tobacco product regulation in some countries has 
been additionally complicated by the introduction of novel heated tobacco products (HTPs). HTPs heat but do not burn tobacco, producing an aerosol with nicotine that does not contain or has lower levels of many of the harmful chemicals in cigarette smoke. ${ }^{45}$ However, current evidence on the harmful effects of HTPs compared with conventional cigarettes is yet to be determined as most of the available evidence is in vitro and comes from tobacco industry-funded research. ${ }^{6-9}$ In July 2020, the Food and Drug Administration (FDA) authorised Philip Morris to make claims in its HTP (IQOS) marketing about reduced exposure to harmful constituents compared with cigarettes; however, the FDA prohibited marketing claims about reduced risks from IQOS use, citing the lack of evidence for this claim. ${ }^{10}{ }^{11}$ Nevertheless, consumers equate reduced exposure with reduced risk ${ }^{12}$ : HTPs appeal to adult smokers and use of HTPs has been rapidly increasing in some high-income countries (HIC) where they have been introduced, suggesting a potential public health benefit, similar to that of e-cigarettes. ${ }^{13-15}$ Nonetheless, the appeal of HTPs among adolescents, particularly those who would otherwise not use tobacco, is relatively unknown.

IQOS was introduced in some countries in 2014 , and is advertised as a less harmful alternative for smokers who want to reduce exposure to harmful chemicals produced by tobacco combustion. ${ }^{16}$ By 2020 , it was available in at least 52 countries worldwide, including Guatemala, ${ }^{4} 17$ but due to the fairly recent introduction to the market, little is known about its awareness and use, particularly among adolescents. Nonetheless, HTPs appear to quickly penetrate markets: for example, among young adults in South Korea, only 3 months after IQOS was introduced into the market, $38 \%$ were aware of the product and $3.5 \%$ were current users. ${ }^{18}$ Additionally, in 2018, a study of older adolescents (16-19 years old) in England, Canada and the USA (where HTPs were either only available in limited areas or not available at the time of the study) reported that among all participants, $7 \%$ were aware of IQOS, $45 \%$ susceptible to future use and $38 \%$ interested in trying IQOS; these percentages were higher in the current smoker and e-cigarette user subpopulation. ${ }^{19}$ Notably, susceptibility to IQOS use $(25 \%)$ was higher than susceptibility to conventional cigarette use (19\%) among never smokers or e-cigarette users, suggesting its potential appeal among adolescents who otherwise would not use tobacco products. ${ }^{19}$

To the best of our knowledge, only one study has reported rates of HTP use among adolescents: this study, from 2019, found that among South Koreans aged 12-18 years, ever use was $2.8 \% .{ }^{20}$ Studies among adults in HICs have shown that HTP awareness and use tends to be higher among males, young adults, cigarette and e-cigarette smokers, and smokers with intentions to quit-all consistent risk factors for e-cigarette use. ${ }^{18} 2122$ Although currently the correlates of HTP use among adolescents are relatively unknown, they may resemble those for e-cigarette use: male, current or ever smoker, having peers or parents who smoke, sensation seeking and technophilia. Some of these factors are hypothesised to be related to e-cigarette use due to Jessor's problem-behaviour theory, which hypothesises that engaging in one risky behaviour increases the likelihood of engagement in other risky behaviours. ${ }^{23-27}$

\section{Study context}

Guatemala is a middle-income country in Central America that signed and ratified the WHO's Framework Convention on Tobacco Control (FCTC) in 2005. However, as of 2020, the only FCTC-recommended policy that has been implemented is smoke-free environments (Article $8)$, and this has been executed with poor enforcement. ${ }^{28}$ In 2015, the prevalence of adolescent cigarette and e-cigarette use in Guatemala was approximately $13 \%$ and $5.5 \%$, respectively. ${ }^{29}{ }^{30}$ There are no current data on HTP use among adolescents in Latin America, or any other low and middle-income countries (LMIC). This study aims to address this gap by evaluating the prevalence and correlates of HTP awareness, susceptibility and use among adolescents in Guatemala to inform prevention and intervention strategies to target those at highest risk for tobacco use, including use of cigarettes, e-cigarettes and HTPs.

\section{METHODS}

\section{Survey design and data}

Adolescents, grades 8-12, were recruited for this crosssectional study. Based on the official list of private in Guatemala City, 30 schools were conveniently selected from middle to high socioeconomic urban areas and sent invitation letters to participate in the study. Six of these schools declined, 4 of which enrolled only boys or girls and 14 did not respond, leaving 10 participating schools. While students in grades 8-11 were recruited from all participating schools, students in the 12th grade were only recruited from 5 of the 10 participating schools. We obtained both passive consent from parents (ie, a consent letter was sent home with students and parents were able to opt their child out of the study by signing and returning the letter) and assent from participating students. All students in participating grades were invited to complete the survey and no incentive was given to the participants or schools. Data were collected between May and September 2019 using a paper-based, selfadministered, Spanish-language survey on sociodemographics and tobacco product susceptibility, use and risk factors. The survey was previously fielded in Mexico and subsequently adapted for Guatemala and pretested to ensure comprehension. ${ }^{24}$

\section{Patient and public involvement}

The research questions and outcome measures, including the study questionnaire, were based on our previous research on e-cigarettes in Guatemala and Mexico. ${ }^{13}$ The instrument was piloted among Guatemalan adolescents 
from schools not included in the study sample to ensure comprehension, and further edited by local researchers to fit the country-specific environment. Participating schools were involved prior to data collection and asked to review the study protocol. Certain schools requested that the study team include 12th graders along with the proposed younger grades in the study sample, and this was accommodated by the study team. Schools were aware of the time required to complete the survey and surveys were only conducted in the time and place allocated by each school. Additionally, a letter of support from the Ministry of Health National Commission for the Prevention and Control of Chronic Disease was obtained prior to the start of the study. Results of this study will be shared with enrolled schools and support will be granted to develop and tailor tobacco use control strategies. Results will also be disseminated to authorities and stakeholders for policy development.

\section{Outcome variables}

We first assessed HTP awareness (yes, no) by showing an image and description of an IQOS, the only HTP available in Guatemala, and asking if participants had previously heard of them. Susceptibility to future HTP use was then assessed for all participants with a single question adapted from Pierce $e t a l$ s validated scale. ${ }^{31}$ This question (prompt: 'If one of your friends offered you a heated tobacco product like IQOS, would you use it?'; possible responses: 'Definitely yes', 'Probably yes', 'Probably no', 'Definitely no') has been shown to predict smoking initiation with the same accuracy as the full scale among Latin American youth. ${ }^{32}$ Those who answered 'Definitely yes', 'Probably yes' or 'Probably no' were considered susceptible to continued or future use, while those who reported 'Definitely no' were categorised as unsusceptible, similar to prior studies. ${ }^{24}$ Students did not need to be previously aware of HTPs to be susceptible to future use. Students were also asked if they had ever tried HTPs (yes, no) and, to assess current use, if they had used HTPs in the prior 30 days. Using the above described definitions, HTP use was characterised as the following four exclusive categories: never used and unsusceptible to future use; never used but susceptible to future use; ever used, but not currently; and current use.

\section{Independent variables}

Sociodemographic variables that were assessed included sex (male, female), age (continuous), grade (8th-9th vs 10th-12th), school performance (averaging $<80 \%$, $80 \%-89 \%$ or $>90 \%)$, highest educational attainment by either parent (primary school or less, high school or technical school, university or more) and family affluence. To assess family affluence, we used the four-item Family Affluence Scale (ie, 'How many cars does your family have?', 'Do you have your own bedroom?', 'How many times did your family go on vacation last year?' and 'How many computers are in your house?'), which is a summative measure validated among other adolescent populations. ${ }^{33}$

Established risk factors for smoking and e-cigarette use were also considered, including other substance use (eg, tobacco products, alcohol, drugs). Use of cigarettes and e-cigarettes was queried and derived consistent with our definition for HTP use (never used and unsusceptible to future use; never used but susceptible to future use; ever used, but not currently; and current use). Additionally, we assessed ever use of any tobacco product (yes/no), first product used among ever users (cigarette, e-cigarette, HTP, other) and dual use of products (yes/no; if yes, which products). Ever use of alcohol, current use (last 30 days) and recent binge drinking (four or more drinks in one sitting in the last 30 days) were assessed and used to derive exclusive categories. We also considered ever and current marijuana use. Smoking, e-cigarette and HTP use was measured separately for both family members (yes, no) and friends (yes, no among five closest friends).

Other common risk factors for smoking and vaping that were considered in this study included frequency of exposure to internet advertising (ie, never; rarely/sometimes; often/very often) for both smoking and e-cigarettes, assessed separately. Sensation seeking (in accordance with Jessor's problem-behaviour theory) was evaluated with four items (ie, 'I would like to explore strange places', 'I like to do things that scare me', 'I like new and exciting experiences, even when I am breaking the rules' and 'Sometimes I do crazy things just for fun') with Likert responses ( $1=$ strongly disagree; $5=$ strongly agree) and averaged together $(\alpha=0.77)$. We also measured 'technophilia', which is a positive orientation towards new technology adoption, using seven items that have been previously shown to independently predict e-cigarette, but not smoking, initiation (ie, having internet access in their room; having a laptop in their room; owning a tablet; having a cellphone with internet access; frequency of using social media; enjoyment from using the internet; level of interest in new technologies). ${ }^{3435}$

\section{Statistical analysis}

Binary logistic regression was used to estimate crude ORs for the association between each independent variable and key outcomes: (1) HTP awareness (yes, no) among all participants; (2) susceptibility to future HTP use (yes, no) among all participants; (3) ever HTP use (yes, no) among non-current users; and (4) current HTP use (yes, no) among all participants. A cut-off of less than $5 \%$ missing was a necessary criterion for inclusion of each variable in the models. However, no variables had more than $5 \%$ missing data, and thus all were included in the final analyses. Parent educational attainment was borderline $(4.8 \%)$ so a 'missing' category was included for this variable. Due to the low prevalence of HTP use, particularly current use, categories of cigarette, e-cigarette and alcohol use were collapsed in some models to increase small cell counts. In the current HTP use model, cigarette and e-cigarette use was collapsed to non-current versus 
current and alcohol was collapsed to non-recent binge versus recent binge. Next, for each outcome, multivariate logistic regression models were calculated to estimate the adjusted ORs (AORs) associated with each independent variable, adjusting for all other independent variables. Crude and adjusted models included a random intercept to adjust for non-independence of observations within schools. In all models, we evaluated collinearity among independent variables by examining the variance inflation factor, and results indicated no collinearity concerns. Also, due to concern regarding the strong influence of friend use of e-cigarettes, we reran the full models after removing this variable and compared results with the original model. There were minimal differences in the coefficients across models, and the direction, statistical significance and interpretation are the same across model specifications. Because of the importance of peer influence for youth tobacco use, we report on the results from the original model that includes the friend use of e-cigarettes variable. All analyses were conducted in R V.3.4.4.

\section{RESULTS}

\section{Participants}

At the 10 schools, 3311 students were invited to participate and 2870 (87\%) completed the survey: $271(8 \%)$ were absent, $135(4 \%)$ did not have permission from their parents, $28(<1 \%)$ refused and $2(<1 \%)$ did not speak Spanish. Five $(<1 \%)$ students who did not complete the survey gave no reason as to why they did not wish to participate.

About half of participants were male and the mean age was slightly over 15 years (table 1 ). Most respondents were in the higher grades (grades 10, 11 and 12) (56.9\%), had an average grade of $80 \%$ or higher $(81.2 \%)$ and had at least one parent with a university degree or higher $(74.8 \%)$.

Over half $(52.4 \%)$ of students reported having heard of HTPs and $8.4 \%$ and $2.9 \%$ reported ever use (but not current) and current use of HTPs, respectively. In the entire sample, $52 \%$ were susceptible to future HTP use. In this sample, 939 (32.7\%) students were both previously aware of HTPs and susceptible to future use, while 802 $(27.9 \%)$ were neither previously aware nor susceptible to future use. Furthermore, $563(19.6 \%)$ were previously aware but not susceptible, and $560(19.5 \%)$ were not previously aware but were susceptible. Over half $(58.4 \%)$ had used a tobacco product at some point in their life; most ever tobacco users first used e-cigarettes $(54.0 \%)$ or cigarettes $(43.2 \%)$. Only $1.5 \%$ of ever tobacco users first used an HTP. Nearly half (44\%) of students had never smoked conventional cigarettes and were unsusceptible to future cigarette use, $30 \%$ had tried smoking and $9 \%$ were current smokers. Regarding e-cigarettes, 56\% reported ever use and 28\% currently use e-cigarettes. Of current tobacco users, the majority only used e-cigarettes $(65.9 \%)$ and only $0.5 \%$ currently used HTP but not cigarettes or e-cigarettes.
Table 1 Characteristics of secondary school student participants in Guatemala, $2019(n=2870)$

n

$\%$

\begin{tabular}{|c|c|c|}
\hline \multicolumn{3}{|l|}{ Dependent variables } \\
\hline Aware of HTP & 1503 & 52.4 \\
\hline Susceptible to HTP & 1500 & 52.4 \\
\hline \multicolumn{3}{|l|}{ HTP use } \\
\hline Never (unsusceptible)* & 1993 & 69.6 \\
\hline Never (susceptible)† & 547 & 19.1 \\
\hline Ever (not current) & 241 & 8.4 \\
\hline Current & 84 & 2.9 \\
\hline
\end{tabular}

Sociodemographic characteristics $\mathbf{n} \quad \%$

Sex

$\begin{array}{ccc}\text { Male } & 1438 & 50.3 \\ \text { Female } & 1420 & 49.7 \\ \text { Age (mean, SD) } & 15.09 & 1.32\end{array}$

Grade-US categories

\begin{tabular}{|c|c|c|}
\hline Basico (grades 8-9) & 1238 & 43.1 \\
\hline Bachillerato (grades 10-12) & 1632 & 56.9 \\
\hline \multicolumn{3}{|l|}{ School performance } \\
\hline$<80 \%$ & 523 & 18.8 \\
\hline $80 \%-89 \%$ & 1321 & 47.6 \\
\hline $90 \%-100 \%$ & 932 & 33.6 \\
\hline \multicolumn{3}{|l|}{$\begin{array}{l}\text { Parents' highest educational } \\
\text { attainment }\end{array}$} \\
\hline Secondary school or less & 49 & 1.7 \\
\hline High school or technical school & 537 & 18.7 \\
\hline University or more & 2146 & 74.8 \\
\hline Missing & 138 & 4.8 \\
\hline Substance use variables & $\mathbf{n}$ & $\%$ \\
\hline Ever use of any tobacco product & 1675 & 58.4 \\
\hline
\end{tabular}

Of ever users, first tobacco product used

\begin{tabular}{|c|c|c|}
\hline Cigarette & 456 & 43.2 \\
\hline E-cigarette & 570 & 54.0 \\
\hline HTP & 16 & 1.5 \\
\hline Other & 13 & 1.2 \\
\hline \multicolumn{3}{|l|}{ Cigarette smoker } \\
\hline Never (unsusceptible) ${ }^{\star}$ & 1261 & 44.0 \\
\hline Never (susceptible)† & 754 & 26.3 \\
\hline Ever (not current) & 601 & 21.0 \\
\hline Current & 250 & 8.7 \\
\hline \multicolumn{3}{|l|}{ E-cigarette user } \\
\hline Never (unsusceptible) ${ }^{*}$ & 713 & 25.0 \\
\hline Never (susceptible)† & 545 & 19.1 \\
\hline Ever (not current) & 808 & 28.3 \\
\hline Current & 791 & 27.7 \\
\hline $\begin{array}{l}\text { Of current smokers, whi } \\
\text { used }\end{array}$ & & \\
\hline
\end{tabular}

Continued 


\begin{tabular}{|c|c|c|}
\hline & $\mathbf{n}$ & $\%$ \\
\hline Only cigarettes & 48 & 5.7 \\
\hline Only e-cigarettes & 556 & 65.9 \\
\hline Only HTPs & 4 & 0.5 \\
\hline More than one product & 236 & 30.0 \\
\hline \multicolumn{3}{|l|}{ Of current HTP users } \\
\hline Also smoke cigarettes & 44 & 52.4 \\
\hline Also smoke e-cigarettes & 78 & 92.9 \\
\hline \multicolumn{3}{|l|}{ Alcohol user } \\
\hline Never & 683 & 23.9 \\
\hline Ever (not current) & 935 & 32.7 \\
\hline Current (no binge) & 676 & 23.7 \\
\hline Current (binge) $\ddagger$ & 561 & 19.6 \\
\hline \multicolumn{3}{|l|}{ Marijuana user } \\
\hline Never & 2563 & 90.2 \\
\hline Ever (not current) & 177 & 6.2 \\
\hline Current & 103 & 3.6 \\
\hline \multicolumn{3}{|l|}{ Internet cigarette ad exposure } \\
\hline Never & 980 & 34.5 \\
\hline Rarely/sometimes & 1543 & 54.3 \\
\hline Mostly/always & 319 & 11.2 \\
\hline \multicolumn{3}{|l|}{ Internet e-cigarette ad exposure } \\
\hline Never & 881 & 31.0 \\
\hline Rarely/sometimes & 1471 & 51.8 \\
\hline Mostly/always & 490 & 17.2 \\
\hline Family member smokes cigarettes & 1025 & 35.8 \\
\hline Family member uses e-cigarettes & 599 & 21.0 \\
\hline Family member uses HTP & 395 & 13.8 \\
\hline Friend smokes cigarettes & 1551 & 54.1 \\
\hline Friend smokes e-cigarettes & 1817 & 63.6 \\
\hline Friend uses HTP & 423 & 14.8 \\
\hline Constructed scales (score range) & Mean & SD \\
\hline Sensation seeking (1-4) & 2.77 & 0.7 \\
\hline Technophilia (0-7) & 5.73 & 0.9 \\
\hline Family Affluence Scale (0-9) & 7.27 & 1.57 \\
\hline
\end{tabular}

*Unsusceptible is defined as answering definitely no to both 'Do you think you will smoke in the next 12 months?' and 'If one of your best friends offered you a cigarette, would you smoke it?' †Susceptible is defined as answering probably no, probably yes or definitely yes to either 'Do you think you will smoke in the next 12 months?' or 'If one of your best friends offered you a cigarette, would you smoke it?'

łBinge drinking is defined as consuming four or more drinks on one occasion in the last month HTP, heated tobacco product.

Considering other substances, one-quarter (24\%) reported never consuming alcohol and 20\% reported at least one instance of binge drinking in the past 30 days. Most (90.2\%) had never used marijuana. About
$50 \%$ of students report seeing online cigarette or e-cigarette advertising rarely or sometimes when they use the internet. Family use of cigarettes, e-cigarettes or HTPs was $35.8 \%, 21.0 \%$ and $13.8 \%$, respectively. Concerning friend cigarette, e-cigarette or HTP use, the corresponding percentages were $54.1 \%, 63.6 \%$ and $14.8 \%$, respectively.

\section{Factors associated with HTP awareness and susceptibility}

About half $(52.4 \%)$ of students reported awareness of HTPs. HTP awareness was higher for ever users (AOR=1.65, 95\% CI 1.23 to 2.21) and current users of e-cigarettes (AOR=2.10, 95\% CI 1.47 to 2.99), binge drinkers (AOR $=1.84,95 \%$ CI 1.28 to 2.65 ) and those exposed to medium (AOR=1.39, 95\% CI 1.10 to 1.75$)$ and high levels of online e-cigarette advertising $(\mathrm{AOR}=1.76$, 95\% CI 1.26 to 2.46) (table 2). Additionally, family smoking (AOR=1.31, 95\% CI 1.07 to 1.60 ) and HTP use (AOR=1.60, 95\% CI 1.22 to 2.09), family affluence (AOR $=1.10,95 \%$ CI 1.04 to 1.17) and friend HTP use (AOR=4.15, 95\% CI 3.11 to 5.55$)$ were positively associated with participant HTP awareness.

In the entire sample, $52.4 \%$ were susceptible to continued or future HTP use. Compared with unsusceptible never smokers, higher susceptibility was found among susceptible never smokers $(\mathrm{AOR}=6.18,95 \%$ CI 4.72 to 8.07 ), ever smokers (AOR=6.93, 95\% CI 5.02 to 9.57) and current smokers (AOR $=10.53$, 95\% CI 5.92 to 18.71), as well as susceptible never (AOR $=12.18,95 \%$ CI 7.79 to 19.03 ), ever (AOR=11.08, 95\% CI 7.07 to 17.37 ) and current e-cigarette users (AOR=21.87, 95\% CI 13.02 to 36.71$)$, compared to unsusceptible never e-cigarette users. Similarly, ever (AOR=1.73, 95\% CI 1.25 to 2.41), current (AOR=1.49, 95\% CI 1.03 to 2.17) and binge drinkers (AOR $=1.65,95 \%$ CI 1.04 to 2.60 ), and current marijuana users (AOR=3.49, 95\% CI 1.40 to 2.60$)$ were more likely to be susceptible to HTP use, compared to never-drinkers/users. Finally, having a friend who used HTPs (AOR $=1.83,95 \%$ CI 1.31 to 2.57 ) and higher sensation-seeking scores (AOR=1.41, 95\% CI 1.19 to 1.68) were positively associated with HTP susceptibility.

\section{Factors associated with HTP use (ever and current)}

Among non-current HTP users, $8.6 \%$ had tried HTPs. Students who were ever smokers $(\mathrm{AOR}=3.73,95 \%$ CI 2.03 to 6.82 ) or current smokers (AOR $=6.63,95 \%$ CI 3.20 to 13.74 ), or ever (AOR=9.31, 95\% CI 2.61 to 33.23) or current e-cigarette users (AOR=10.40, 95\% CI 2.75 to 39.17) were more likely to be ever HTP users than corresponding unsusceptible non-users (table 3). Those who reported binge drinking ( $\mathrm{AOR}=2.53,95 \%$ CI 1.08 to $5.95)$ and marijuana use (AOR=2.29, $95 \%$ CI 1.27 to 4.13 ) were also more likely to be ever HTP users than nonusers. Family smoking (AOR=1.70, 95\% CI 1.19 to 2.45) and friend HTP use (AOR=7.28, 95\% CI 4.64 to 11.43) were associated with higher odds of ever use of HTPs. Higher family affluence was also associated with ever use (AOR $=1.15,95 \%$ CI 1.02 to 1.31 ). 


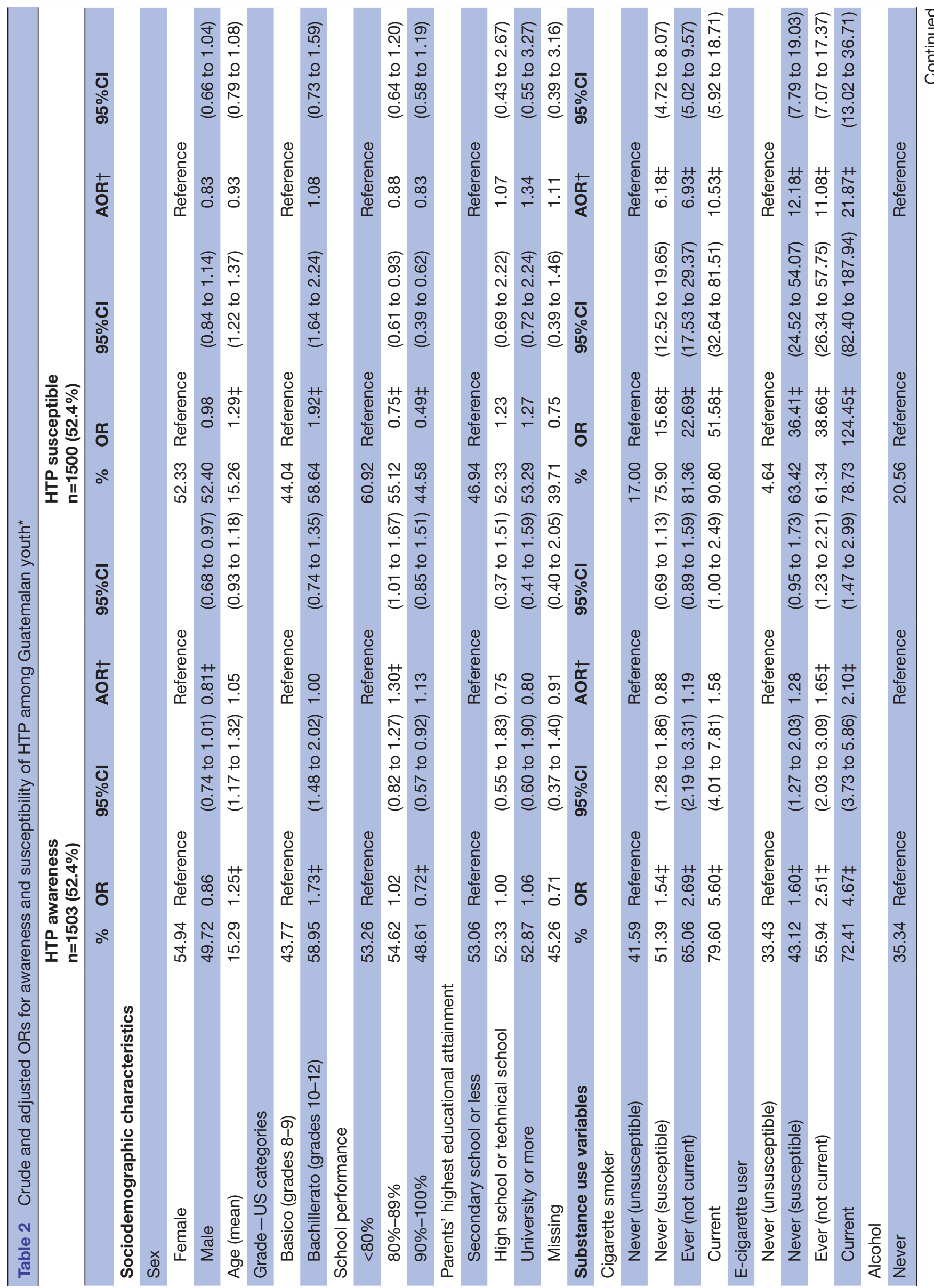

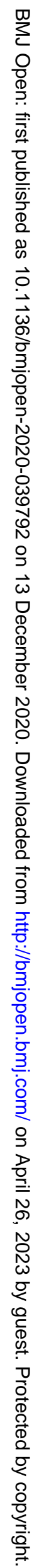




\section{ชิㄷํㅇ \\ ง \\ 웅 \\ กิ ๆ \\ ᄃ $匚$}

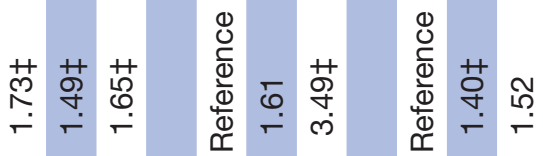

बิ

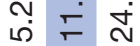

ㅇㅇㅇㅇ

ल ऍ ॠ

ल) $\stackrel{\oplus}{=}$

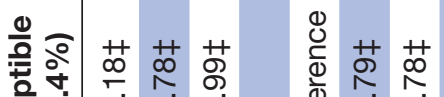

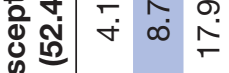

สิ

ले

우

$\infty$ ㅇ

Е ำ

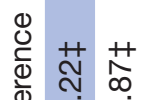

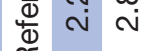

$\llbracket$

$\stackrel{\sim}{\sim} \underset{0}{\infty} \stackrel{\infty}{\wedge}$
के 8

क

₹

กิ่

웅

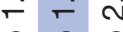

우우 우

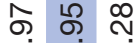

은

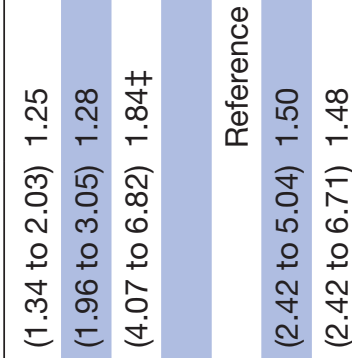

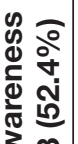

亲觉

峁

우 $\infty$ 迥

तิ

i $N$

の

¿

$\stackrel{Ð}{\circlearrowleft}$

苔莳苍离蒂

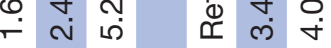
ฉ 守

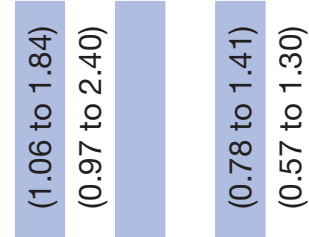

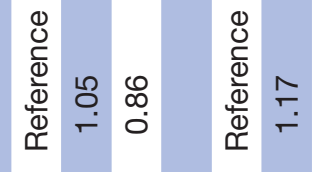
象

每令

둥

$\infty \stackrel{\circ}{\sim}$

e

ญ

㐫 웅

ब유

ले

요 웅

아

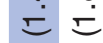

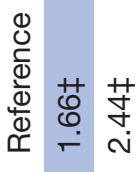

궁 棺

\section{๙ุ \\ 웅 \\ 낭 으 \\ ¿ุ}

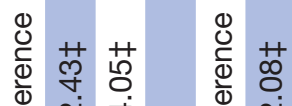
过

$\widetilde{1}$

$\stackrel{\sim}{\sim}$

ம่

怔

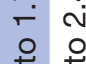

우 웅

E

ญ

迹 苍

व ले

\begin{tabular}{l} 
कू \\
N \\
N \\
\multirow{\gamma}{*}{}
\end{tabular}

$+\circ$

๑ั ชิ

亡
号

崩

ㅇำ

लिं

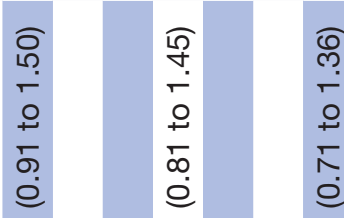

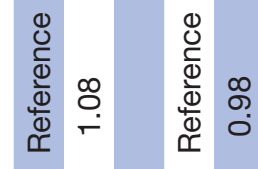

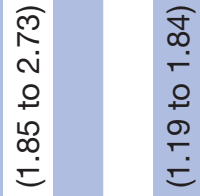

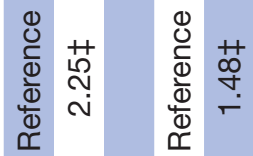

요 $\infty$

文

穴 ร

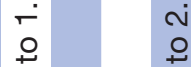

๙ N

อ

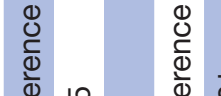

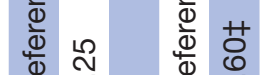

ॠ

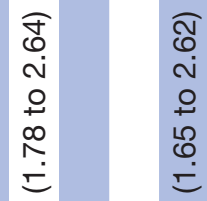

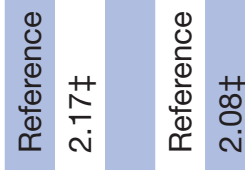

๑

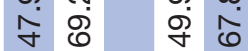

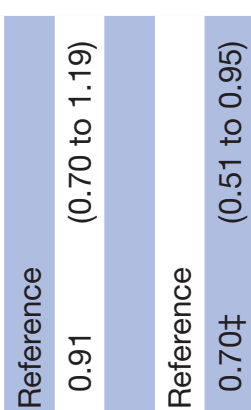

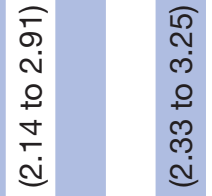

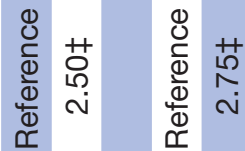

$\circ \infty \infty$ ช่ ชิ

న़ ন़

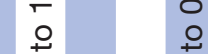

$\infty$

อ อ

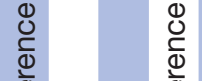

迹

o

กู

웅

กิ

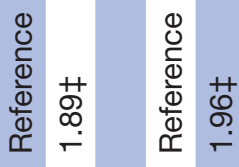

ก

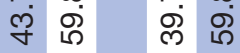

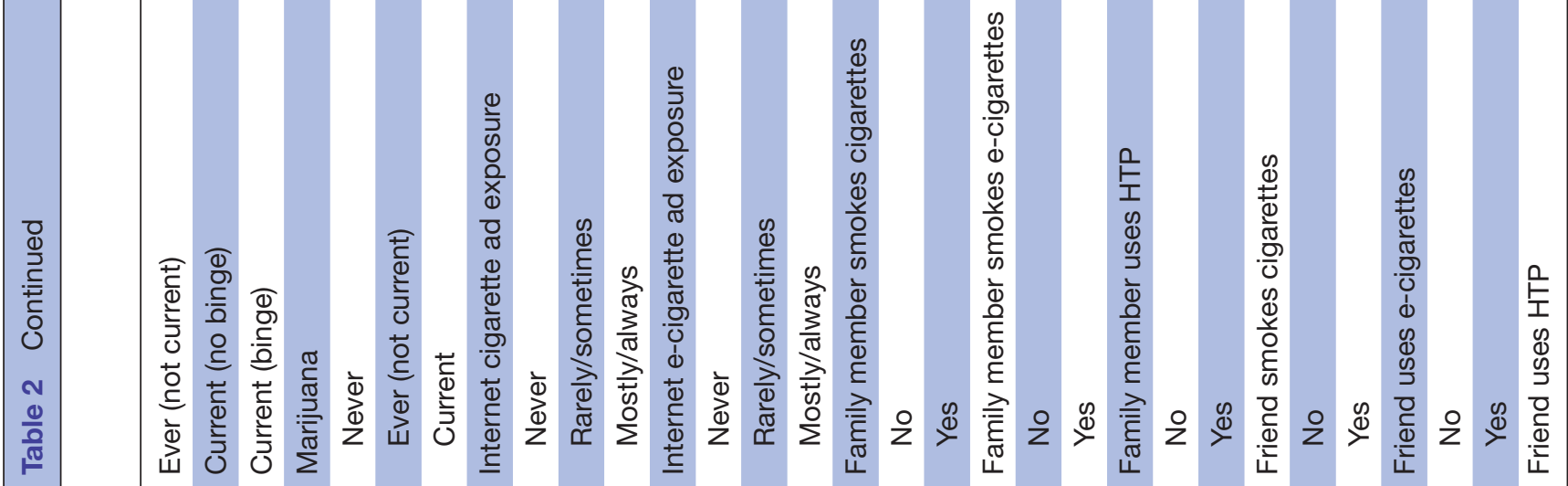




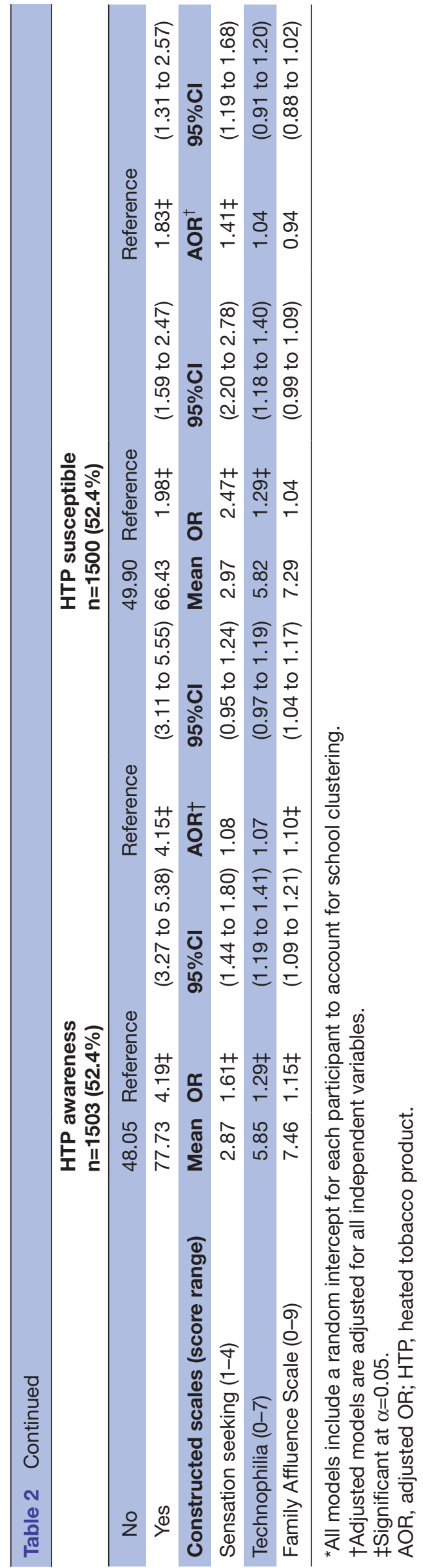

In the overall population, $2.9 \%$ were current HTP users. The odds of current HTP use was higher for both cigarette (AOR=3.90, 95\% CI 1.90 to 8.02) and e-cigarette users (AOR $=46.12,95 \%$ CI 16.15 to 131.74 ). Having family members who smoked (AOR=2.00, 95\% CI 1.03 to 3.88) and friends who used HTPs (AOR=21.06, 95\% CI 11.13 to 39.85) was associated with higher odds of current use of HTPs.

\section{DISCUSSION}

We investigated HTP use among adolescents in private schools in Guatemala City, where HTPs are becoming readily available ${ }^{36}$ About half of the students were aware of HTPs (54.2\%) and susceptible to future use of HTPs $(54.2 \%)$, although ever (but not current) HTP use $(8.4 \%)$ and current HTP use $(2.9 \%)$ were low compared with smoking $(21.0 \%$ and $8.7 \%$, respectively) and e-cigarette use $(28.3 \%$ and $27.7 \%$, respectively). Furthermore, almost none of the students who had ever used any tobacco product reported using HTPs as their first tobacco product (1.5\%), and nearly all current HTP users also either smoked cigarettes $(52.4 \%)$ or used e-cigarettes $(92.9 \%)$. These results suggest that in this population HTPs are not a gateway tobacco product, as has been reported for e-cigarettes in many locations, including in Latin America, even though there is evidence against this claim. ${ }^{37-39}$ However, the high prevalence of susceptibility to future use that we found suggests that this may change if HTPs become more popular or accessible.

Currently, the available data on HTP awareness and use are from HICs, which have stronger tobacco control policies, making cross-country comparisons challenging. One study of adolescents aged 16-19 years in Canada, the USA and England ${ }^{19}$ found lower levels of awareness $(7.0 \%)$ and susceptibility $(45.0 \%)$ compared with our sample (52.4\% and $52.4 \%$, respectively). However, this study only included never smokers and never vapers. As we found that HTP susceptibility was associated with smoking and e-cigarette use, it is unsurprising that rates are higher in our study population, which included participants who reported tobacco use. Additionally, use of alcohol or marijuana, family and friend use of tobacco products and higher sensation seeking were all positively associated with susceptibility to continued and future use of HTPs in adolescents; these variables have not been previously studied among HTP users, but the associations we found are not unexpected given prior research on e-cigarette susceptibility and use. ${ }^{23-26}$ In the end, our results support Jessor's problem-behaviour theory, which hypothesises that substance use and other risk behaviours tend to cluster together. ${ }^{27}$

To our knowledge, the only other study of adolescents' current use of HTPs comes from South Korea. ${ }^{20}$ This 2019 study among Korean adolescents aged 12-18 years found lower ever-use HTP rates than in our sample $(2.8 \%$ vs $8.4 \%$ ), despite the fact that HTPs have been on the market for longer in Korea than Guatemala. ${ }^{20}$ While South Korea has a much higher gross domestic product per capita 


\begin{tabular}{|c|}
\hline 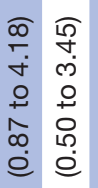 \\
\hline
\end{tabular}

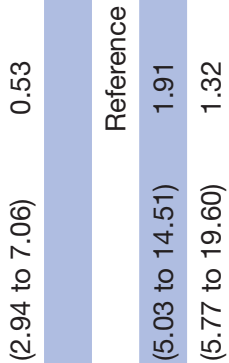

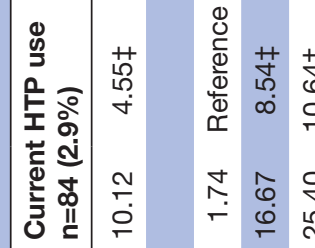

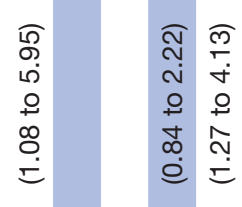

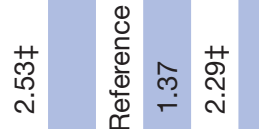

\section{Ð \\ 产

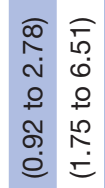

$\stackrel{Ð}{\mathscr{\Xi}}$

这

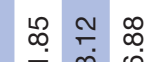

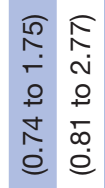

ญ

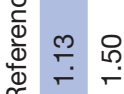

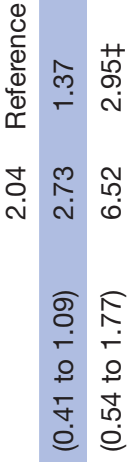

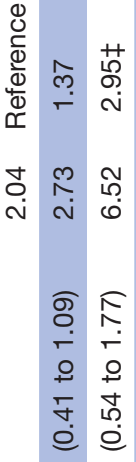

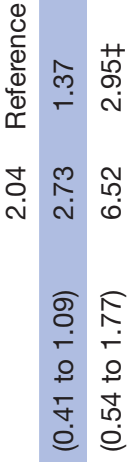

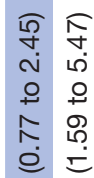

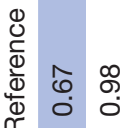

造

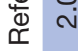

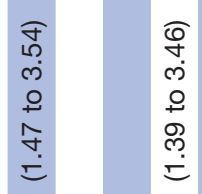

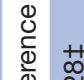
㐫 ธิ

\section{Ð \\ 岕 \\ 辛}

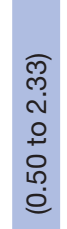

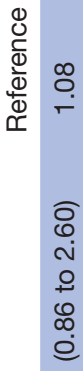

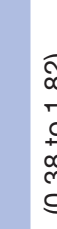

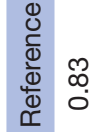

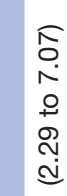

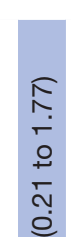

Ð

迹

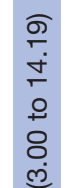

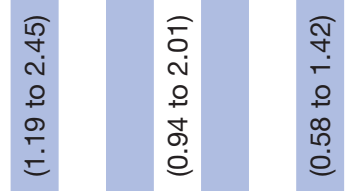

离

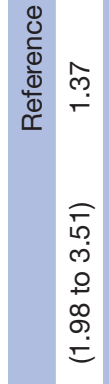

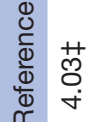 \\ $\simeq$}

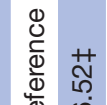
ष्य ๑

\section{Ð}

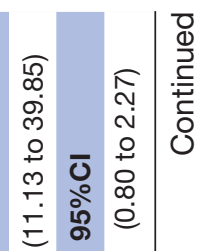

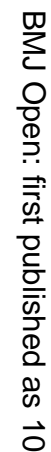

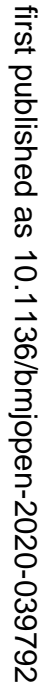

인

$\vec{\omega}$

叫

궁

N

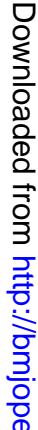

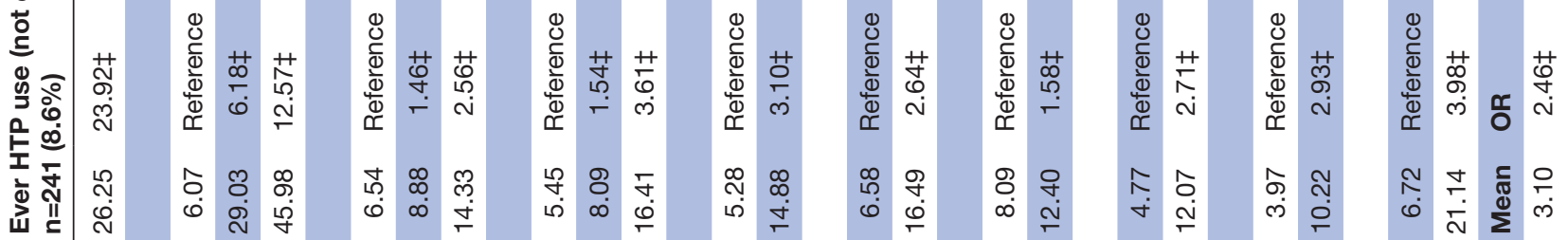

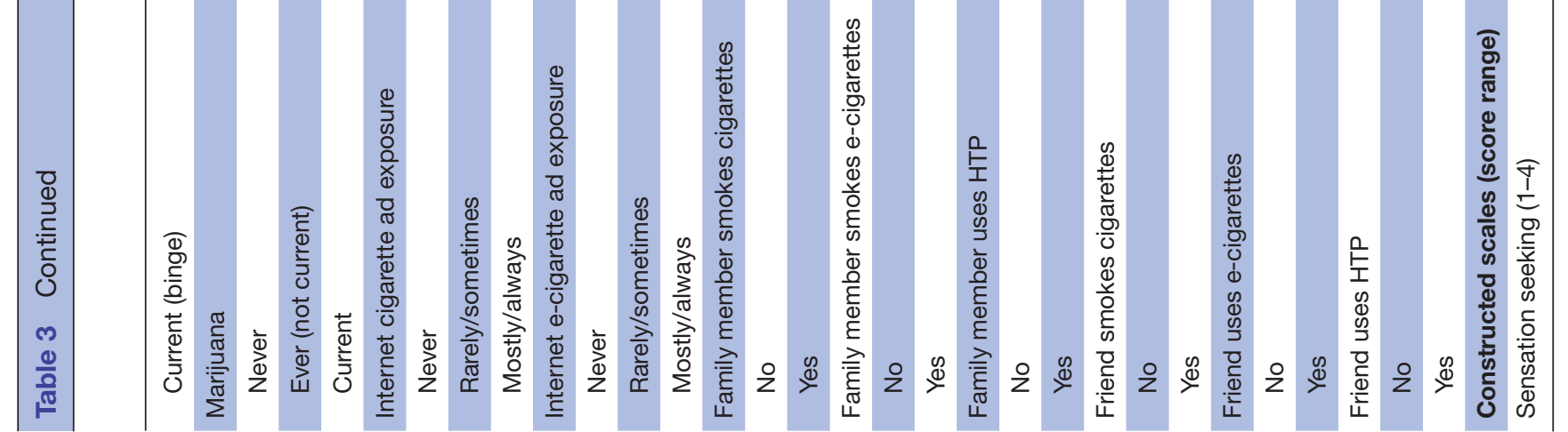

क

$+ㅇ$

孞
ลิ

우

m

긴

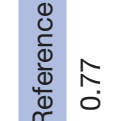

Ð

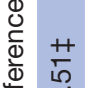

$\stackrel{8}{\square}$

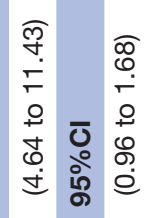

岕 
than Guatemala, our study population was selected from private schools in middle and high socioeconomic status (SES) neighbourhoods in Guatemala City, which are predominantly attended by students of significant higher SES, and this could be the cause of the discrepancy. For example, the average monthly cost to attend one of the schools in our study is US\$388-US\$420 plus an annual enrolment fee of an average US $\$ 550$, and a 2020 report from the World Bank ${ }^{40}$ found that about $50 \%$ of Guatemalans live below the upper middle-income poverty line of about US $\$ 165$ per month. However, according to the 2018 census, $37 \%$ of middle school students and $70 \%$ of high school students in Guatemala City attend private schools. Therefore, our results may be generalisable to Guatemala City, but not the entire country. ${ }^{41}$ Our study goes beyond the study from Korea by assessing correlates of use, which appear similar to those for e-cigarette use among adolescents. ${ }^{23-25}$ For example, correlates of HTP use in our study are also predictors of e-cigarette use in Mexico (use of cigarettes, alcohol and marijuana, family use of cigarettes and sensation-seeking behaviour) ${ }^{23} \mathrm{We}$ also found that e-cigarette use was a correlate of HTP use.

To the best of our knowledge, our study is the first to assess HTP awareness or use among adolescents from LMICs. Furthermore, we conducted a study in a country with weak FCTC implementation where HTPs, e-cigarettes and cigarettes are all readily available. In addition, we used a previously implemented survey that includes novel predictors (eg, technophilia, sensation seeking) of non-conventional tobacco product use. However, our results must be interpreted in the context of the study's limitations. All data were self-reported, although the directionality of any biases is not clear. This resulted in an expected amount of uncertainty due to misreporting. The sample was recruited from private schools, which predominantly serve middle and high-income students. Therefore, generalisability to the entire country is limited. Additionally, only four students exclusively used HTPs (ie, did not also smoke or use e-cigarettes), and thus it is hard to draw conclusions about this group. Because of this, model estimates include some large ORs (with similarly large CIs) when examining associations between HTP use and other tobacco product use. These estimates could be made more precise with larger sample sizes, but they may also reflect the fact that HTP use typically follows use of other tobacco products and substances-in other words, at this time HTPs do not appear to be a 'gateway' product for Guatemalan youth. Finally, the data are cross-sectional and so preclude causal inference for some time-varying variables in the analyses.

Despite its limitations, this study is the first of its kind to examine HTP use and its correlates among adolescents in an LMIC. While current HTP use was low in our study, awareness and susceptibility were high and therefore use of IQOS and other HTP products might increase as they become more widely available. Particularly concerning is the introduction of flavoured HTPs in some countries, which involves the addition of sticks with flavour capsules 
in the filter that the consumer can crush to make the aerosol taste like diverse flavours, ranging from mint to ginger to bubble gum. ${ }^{42}$ Flavour capsules in cigarettes, which include an even broader range of flavours (eg, mango, mint, berry) that are popular with youth, are increasingly popular worldwide, including in Guatemala, where they represented $32 \%$ of the cigarette market in $2017 .^{43}$ While it does not seem like HTPs are gateway tobacco products for adolescents, as most current users in our sample report initially using e-cigarettes, as HTPs become more common and integrate new flavours and flavour technologies, it is possible that this could change, particularly among adolescents. It is critical to identify adolescents at risk for tobacco product uptake (cigarette, e-cigarette, HTPs, and so on) so that FCTC policies can be adequately designed and implemented in a manner prioritised for this high-risk group. Future studies should investigate whether rates of HTP use and predictors for HTP use are similar among other populations in Guatemala, including adults and other socioeconomic groups, as well as explore how adolescent e-cigarette users transition to HTP use.

\section{Author affiliations}

${ }^{1}$ Instituto de Investigación y Estudios Superiores en Ciencias de la Salud, Universidad Rafael Landivar, Guatemala, Guatemala

${ }^{2}$ School of Population and Public Health, The University of British Columbia, Vancouver, British Columbia, Canada

${ }^{3}$ Department of Health Promotion, Education and Behavior, University of South Carolina, Columbia, South Carolina, USA

${ }^{4}$ Center for Population Health Research, National Institute of Public Health, Cuernavaca, Morelos, Mexico

${ }^{5}$ Departamento de Investigacion, Unidad de Cirugia Cardiovascular, Guatemala, Guatemala

\section{Twitter Anna Gottschlich @annagottschlich and Jose Carlos Monzon @mishoo8}

Contributors AG: analysis design and execution, drafted the manuscript. SM, JCM: study design, questionnaire design, data collection, manuscript review and approval. JFT: study design, questionnaire design, analysis design, manuscript review and approval. JB: study design, questionnaire design, data collection, manuscript review and approval, stakeholder engagement.

Funding This work was supported by Fogarty International Center of the National Institutes of Health under award number R01 TW010652.

Disclaimer The content is solely the responsibility of the authors and does not necessarily represent the official views of the National Institutes of Health.

Competing interests None declared.

Patient and public involvement Patients and/or the public were involved in the design, or conduct, or reporting, or dissemination plans of this research. Refer to the Methods section for further details.

Patient consent for publication Not required.

Ethics approval This protocol was approved by the Institutional Ethics Committee of the Institute of Nutrition of Central America and Panama (INCAP) (approval number 087/2019).

\section{Provenance and peer review Not commissioned; externally peer reviewed.}

Data availability statement Data are available upon reasonable request. The data sets used and/or analysed during the current study are available from the corresponding author on reasonable request.

Open access This is an open access article distributed in accordance with the Creative Commons Attribution Non Commercial (CC BY-NC 4.0) license, which permits others to distribute, remix, adapt, build upon this work non-commercially, and license their derivative works on different terms, provided the original work is properly cited, appropriate credit is given, any changes made indicated, and the use is non-commercial. See: http://creativecommons.org/licenses/by-nc/4.0/.

\section{ORCID iDs}

Anna Gottschlich http://orcid.org/0000-0002-3095-2323

Joaquin Barnoya http://orcid.org/0000-0002-1731-479X

\section{REFERENCES}

1 Demissie Z, Everett Jones S, Clayton HB, et al. Adolescent risk behaviors and use of electronic vapor products and cigarettes. Pediatrics 2017;139:e20162921.

2 Carroll Chapman SL, Wu L-T. E-Cigarette prevalence and correlates of use among adolescents versus adults: a review and comparison. $J$ Psychiatr Res 2014;54:43-54.

3 Frieden TR, Jaffe HW, Richards CL. E-Cigarette use among youth and young adults. A report of the surgeon General. Ga: US, 2016.

4 WHO. Heated tobacco products (HTPS) information sheet. WHO, 2018: 2-3.

5 Auer R, Concha-Lozano N, Jacot-Sadowski I, et al. Heat-not-burn tobacco cigarettes: smoke by any other name. JAMA Intern Med 2017;177:1050-2.

6 Nabavizadeh P, Liu J, Havel CM, et al. Vascular endothelial function is impaired by aerosol from a single IQOS HeatStick to the same extent as by cigarette smoke. Tob Control 2018;27:s13-19.

7 Drovandi A, Salem S, Barker D, et al. Human biomarker exposure from cigarettes versus novel Heat-Not-Burn devices: a systematic review and meta-analysis. Nicotine Tob Res 2020;22:1077-85.

8 Leigh NJ, Tran PL, O'Connor RJ, et al. Cytotoxic effects of heated tobacco products (HTP) on human bronchial epithelial cells. Tob Control 2018;27:s26-9.

9 Stepanov I, Woodward A. Heated tobacco products: things we do and do not know. Tob Control 2018;27:s7-8.

10 U.S. Food and Drug Administration. Modified risk grant orders exposure modification: MR0000059-MR0000061, MR0000133, 2020.

11 U.S. Food and Drug Administration. FDA Authorizes Marketing of IQOS Tobacco Heating System with 'Reduced Exposure' Information. 10-3, 2020. Available: https://www.fda.gov/newsevents/press-announcements/fda-authorizes-marketing-iqostobacco-heating-system-reduced-exposure-information

12 Popova L, Lempert LK, Glantz SA. Light and mild redux: heated tobacco products' reduced exposure claims are likely to be misunderstood as reduced risk claims. Tob Control 2018;27:s87-95.

13 Cruz-Jiménez L, Barrientos-Gutiérrez I, Coutiño-Escamilla L, et al. Adult smokers' awareness and interest in trying heated tobacco products: perspectives from Mexico, where HTPs and e-cigarettes are banned. Int J Environ Res Public Health 2020;17. doi:10.3390/ ijerph17072173. [Epub ahead of print: 2503 2020].

14 Caputi TL, Leas E, Dredze M, et al. They're heating up: Internet search query trends reveal significant public interest in heat-not-burn tobacco products. PLoS One 2017;12:e0185735-7.

15 Liu X, Lugo A, Spizzichino L, et al. Heat-not-burn tobacco products are getting hot in Italy. J Epidemiol 2018;28:274-5.

16 Philip Morris Inrternational. Tobacco meets technology

17 Glantz SA. Heated tobacco products: the example of IQOS. Tob Control 2018;27:s1-6.

$18 \mathrm{Kim} \mathrm{J}$, Yu H, Lee S, et al. Awareness, experience and prevalence of heated tobacco product, IQOS, among young Korean adults. Tob Control 2018;27:s74-7.

19 Czoli CD, White CM, Reid JL, et al. Awareness and interest in IQOS heated tobacco products among youth in Canada, England and the USA. Tob Control 2019:1-7.

20 Kang H, Cho S-il, II CS. Heated tobacco product use among Korean adolescents. Tob Control 2019:1-3.

21 Nyman AL, Weaver SR, Popova L, et al. Awareness and use of heated tobacco products among US adults, 2016-2017. Tob Control 2018;27:s55-61.

22 Brose LS, Simonavicius E, Cheeseman H. Awareness and Use of 'Heat-not-burn' Tobacco Products in Great Britain. Tob Regul Sci 2018;4:44-50.

23 Thrasher JF, Abad-Vivero EN, Barrientos-Gutíerrez I, et al. Prevalence and correlates of e-cigarette perceptions and trial among early adolescents in Mexico. J Adolesc Health 2016;58:358-65.

24 Morello P, Pérez A, Peña L, et al. Prevalence and predictors of e-cigarette trial among adolescents in Argentina. Tob Prev Cessat 2016;2:1-8.

25 Zavala-Arciniega L, Reynales-Shigematsu LM, Lozano P, et al. Patterns of awareness and use of electronic cigarettes in Mexico, a 
middle-income country that bans them: results from a 2016 national survey. Prev Med 2018;116:211-8.

26 Vardavas Cl, Filippidis FT, Agaku IT. Determinants and prevalence of e-cigarette use throughout the European Union: a secondary analysis of 26566 youth and adults from 27 Countries. Tob Control 2015;24:442-8.

27 Crowther B, Jessor R, Jessor SL. Problem behavior and psychosocial development: a longitudinal study of youth. Contemp Sociol 1978;7:742.

28 Barnoya J, Monzon JC, Briz P, et al. Compliance to the smoke-free law in Guatemala 5-years after implementation. BMC Public Health 2016;16:1-5

29 WHO. Guatemala metropolitan Area-STEPS 2015 fact sheet, 2015: 4-6.

30 Youth G, Survey T, Sheet F, et al. Guatemala 2015, 2015: 3-4.

31 Pierce JP, Choi WS, Gilpin EA, et al. Validation of susceptibility as a predictor of which adolescents take up smoking in the United States. Health Psychol 1996;15:355-61.

32 Morello P, Pérez A, Braun SN, et al. Smoking susceptibility as a predictive measure of cigarette and e-cigarette use among early adolescents. Salud Publica Mex 2018;60:423-31.

33 Boyce W, Torsheim T, Currie C, et al. The family affluence scale as a measure of national wealth: validation of an adolescent self-report measure. Soc Indic Res 2006;78:473-87.

34 Barrientos-Gutierrez I, Lozano P, Arillo-Santillan E, et al.

"Technophilia": A new risk factor for electronic cigarette use among early adolescents? Addict Behav 2019;91:193-200.
35 Zavala-Arciniega L, Lozano P, Kollath-Cattano C, et al. E-Cigarette use frequency and motivations among current users in middle school. Drug Alcohol Depend 2019;204:107585.

36 Barnoya J, Monzon D, Pinetta J, et al. Flavor capsule cigarettes, electronic cigarettes, and heat not burn products point of sale advertising in guatemala. In: The Society for Research on Nicotine and Tobacco. New Orleans, USA, 2020.

37 Soneji S, Barrington-Trimis JL, Wills TA, et al. Association between initial use of e-cigarettes and subsequent cigarette smoking among adolescents and young adults: a systematic review and metaanalysis. JAMA Pediatr 2017;171:788-97.

38 Lozano P, Barrientos-Gutierrez I, Arillo-Santillan E, et al. A longitudinal study of electronic cigarette use and onset of conventional cigarette smoking and marijuana use among Mexican adolescents. Drug Alcohol Depend 2017;180:427-30.

39 Levy DT, Warner KE, Cummings KM, et al. Examining the relationship of vaping to smoking initiation among US youth and young adults: a reality check. Tob Control 2019;28:629-35.

40 The World Bank. Poverty \& Equity Brief: Latin America \& the Caribbean. Guatemala, 2020.

41 Instituto Nacioanl de Estadística Guatemala INE. Xii Censo Nacional de Población Y VII de Vivienda. Guatemala, 2019.

42 Cho YJ, Thrasher JF. Flavour capsule heat-sticks for heated tobacco products. Tob Control 2019;28:e158-9.

43 Moodie C, Thrasher JF, Cho YJ, et al. Flavour capsule cigarettes continue to experience strong global growth. Tob Control 2019;28:595-6. 